\title{
A review of the genus Sphenomorphus Fitzinger, 1843 (Squamata: Scincidae) in southern Vietnam, with additional data on S. sheai and S. tridigitus
}

\author{
Manh Van Le ${ }^{1}$, Luan Thanh Nguyen ${ }^{2}$, Ba Dinh Vo ${ }^{3}$, Robert W. Murphy ${ }^{4}$, Vu Dang Hoang Nguyen ${ }^{5}$, \\ Sang Ngoc Nguyen ${ }^{5, *}$
}

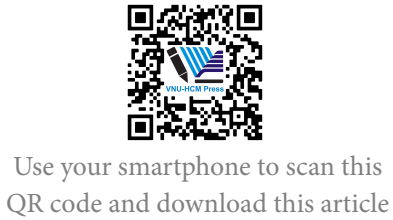

${ }^{1}$ University of Science and Education, University of Danang, 459 Ton Duc Thang St., Lien Chieu District, Danang City, Vietnam

${ }^{2}$ Indo-Myanmar Conservation

${ }^{3}$ University of Science, Hue University

${ }^{4}$ Royal Ontario Museum, Canada

${ }^{5}$ Institute of Tropical Biology, Vietnam Academy of Science and Technology, 85 Tran Quoc Toan St., Dist. 3, Ho Chi Minh City, Vietnam

Correspondence

Sang Ngoc Nguyen, Institute of Tropical Biology, Vietnam Academy of Science and Technology, 85 Tran Quoc Toan St. Dist. 3, Ho Chi Minh City, Vietnam

Email: ngocsangitb@yahoo.com

\section{History}

- Received: 2019-12-02

- Accepted: 2020-02-11

- Published: 2020-03-24

DOI : 10.32508/stdj.v23i1.1733

\section{Check for updates}

Copyright

๑ VNU-HCM Press. This is an openaccess article distributed under the terms of the Creative Commons Attribution 4.0 International license.

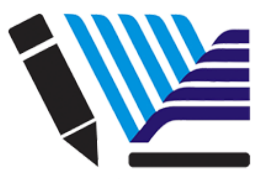

VNU-HCM Press

\begin{abstract}
Introduction: Among 14 species of forest skinks (genus Sphenomorphus) in Vietnam, seven were recorded from southern part of the country. Shea's forest skink, S. sheai, was described from Kon Tum Plateau based on a single female. Similarly, the tridigital forest skink, S. tridigitus, was also described based on a single putrid and desiccated specimen found dead on a road in Bach Ma; specimens collected recently in Laos did not fully agree with the original description. Hence, additional specimens from type localities of both poorly known species are necessary to discern their morphological variation. In addition, little is known about hemipenis and distribution of the other forest skinks in southern Vietnam. Our study seeks to (1) confirm the occurrence of all known species in the area and access their distributions, (2) provide additional morphological data on poorly known S. sheai and S. tridigitus, and (3) describe hemipenial structure of known species. Methods: We analyzed the morphology of 47 specimens of forest skink collected from southern Vietnam to identify species. Scales were observed and counted under a zoom stereo microscope and measurements were taken with a digital caliper. Results: Analyses confirmed the occurrence of seven species of Sphenomorphus in southern Vietnam, including S. annamiticus, S. buenloicus, S. indicus, S. maculatus, S. sheai, S. tridigitus, and S. yersini. New specimens of S. sheai had one enlarged anterior temporal and eight or nine lamellae under fourth toe, which differed from the original description. Additional specimens of S. tridigitus from the type locality verified that the holotype has 20 mid-body scale rows and first supralabial and nasal fused, but they differed from the holotype in having upper temporal overlapped or overlapping the lower one. Fieldwork discovered 20 new localities for all seven species. The hemipenes of four species involved those with symmetric and asymmetric lobes. Conclusion: We confirm the occurrence of seven species of Sphenomorphus in southern Vietnam with 20 additional distribution records. Hemipenial structures of known species form two groups. New specimens of S. sheai and S. tridigitus differ slightly from the holotypes.

Key words: Sphenomorphus sheai, Sphenomorphus tridigitus, forest skink, new record, hemipenis
\end{abstract}

\section{INTRODUCTION}

With 112 species, Sphenomorphus Fitzinger ${ }^{1}$ is one of the most diverse genera of the family Scincidae. The genus has a wide distribution extending from India throughout Southeast Asia and associated islands to Australia $^{2-4}$. The following morphological characters diagnose the genus: lower eyelid scaly, supranasals absent, prefrontals present, parietals in contact behind interparietal, tympanum usually sunk, dorsal scales usually smooth, medial pair of precloacals enlarged, inner precloacals overlapping outer ones, hind limbs with five digits, and symmetrical or asymmetrical forked hemipenis ${ }^{2}$. Nguyen et al. ${ }^{5}$ recorded 11 species of Sphenomorphus in Vietnam, including $S$. bacboensis, S. buenloicus, S. cryptotis, S. indicus, S. maculatus, S. mimicus, S. stellatus, S. tetradactylus, S. tonkinensis, S. tridigitus, and S. tritaeniatus, and provided a key to the species in Vietnam and China. Subsequently, Nguyen et al. ${ }^{6,7}$ added $S$. incognitus from Bac Giang Province and described the new species, $S$. sheai, from the border area between Quang Ngai and Kon Tum provinces. Nguyen et al. ${ }^{2}$ described another new species, S. yersini, from Khanh Hoa Province. Uetz et al. ${ }^{3}$ added $S$. malayanum into the faunal list of Vietnam based on the checklist of Bobrov ${ }^{8}$. However, Bobrov \& Semenov ${ }^{9}$ removed this species from the Vietnamese herpetofauna, and when reviewing Sphenomorphus in Vietnam and describing new species, Nguyen et al. ${ }^{5,7}$ did not include it. Recently, S. annamiticus was resurrected for the populations in southern Vietnam and S. stellatus was reported to be restricted to Peninsular Malaysia ${ }^{4}$. Therefore, Vietnam has 14 species of Sphenomorphus. 
Seven species of Sphenomorphus, including S. annamiticus, S. buenloicus, S. indicus, S. maculatus, S. sheai, S. tridigitus, and S. yersini, occur in southern Vietnam from Bach Ma-Hai Van Mountains southward. Most of these species are documented from a series of specimens ${ }^{2,10}$, but two are the most poorly known species of skinks in Vietnam. Sphenomorphus sheai was described from the female holotype only ${ }^{7}$ and, hence, more samples are necessary to assess its morphological variation. Similarly, S. tridigitus was described from a single specimen collected at Bach $\mathrm{Ma}$, Thua Thien-Hue Province ${ }^{11}$. The second specimen was reported from Bolaven Plateau, Champasak Province, Laos $^{12}$, and subsequently Greer et al. ${ }^{13}$ updated the description and corrected original errors based on this specimen. However, the Laotian sample differs from the holotype by having only 18 mid-body scale rows instead of 20. Heatwole \& Stuart ${ }^{14}$ collected 73 specimens of this skink from Bolaven Plateau, Champasak Province, Laos. This large collection agreed with the redescription of Greer et al. ${ }^{13}$ including discrepancies. However, the number of mid-body scale rows remains unclarified. In Vietnam, Bain et al. ${ }^{15}$ recorded two specimens (IEBR 73 \& 74) from Ngoc Linh, Quang Nam Province that agreed with the redescription of Greer et al. ${ }^{13}$. These samples have a frontonasal, two widely separated prefrontals, fusion of nasal and first "infralabial" (it should be "supralabial") scales, and 18 and 20 mid-body scale rows ${ }^{16}$. Because the holotype was in a poor state of preservation having been found dead on a road ${ }^{13}$ and the additional specimens collected out of the type locality do not fully agree with the original description, more specimens from Bach Ma (type locality) are necessary to clarify the status of this skink.

Our recent field surveys in southern Vietnam yielded additional specimens of $S$. sheai near its type locality, S. tridigitus from its type locality, and all other congeners from southern Vietnam. Therefore, we review the species of Sphenomorphus in southern Vietnam and provide additional data on the morphology of $S$. sheai and S. tridigitus.

\section{MATERIAL AND METHODS}

A total of 47 specimens deposited in the Institute of Tropical Biology Collection of Zoology (ITBCZ, Vietnam Academy of Science and Technology, Ho Chi Minh City) were examined. Scales were observed and counted on the right side under a zoom stereo microscope at 7X-45X (Akeiyo, Hong Kong). Measurements were also taken on the right side with a digital caliper (Exploit $150 \mathrm{~mm}$, China) to the nearest 0.1 $\mathrm{mm}$. Elevation (above see level - a.s.l.) was measured using GPS Garmin 64S (Taiwan). Common English and Vietnamese names followed Nguyen et al. ${ }^{2,7,17}$.

The following morphological characters modified from Nguyen et al. ${ }^{2,7}$ were used: snout-vent length (SVL) measured from the tip of the rostral to the vent; tail length (TaL) measured from the vent to the tip of tail; axilla-groin length $(\mathrm{AxGnL})$ measured from the posterior margin of the forelimb insertion to the anterior margin of the hind limb insertion; snout to forelimb length (SnForeL) measured from the anterior margin of the forelimb insertion to the tip of the rostral; head length (HL) measured from the posterior margin of parietal to the tip of the rostral; head width (HW) measured at the widest portion of the temporal region; supralabials (SL); infralabials (IL); loreals; supraoculars (SO); enlarged temporals (L/U - the lower secondary temporal overlapping the upper one, U/L - the upper secondary temporal overlapping the lower one); nuchal (pair); midbody scale rows (MBS) counted as the number of longitudinal scale rows encircling the body at a point midway between the limb insertions; paravertebral scale rows (ParaVert) counted as the number of scales in a line from the parietal scales to a point on the dorsum opposite the vent; ventral scale rows (Ven) counted as a row of scales between the postmentals and the cloacal plate; enlarged cloacal plate $(\mathrm{L} / \mathrm{R}$ - the left plate overlapping the right one, $\mathrm{R} / \mathrm{L}$ - the right plate overlapping the left one); subcaudal scales (SC) counted as a row of subcaudals between the vent and the tip of tail (paired + single plate); and lamellae beneath the fourth toe (Toe IV) counted from the first scale whose posterior margin extending into the body of the foot. Values of paired characters were recorded in order of left and right. Nomenclature for head shields followed Smith ${ }^{10}$, Ouboter ${ }^{18}$, and Greer ${ }^{13}$.

\section{RESULTS}

Examination of our 47 specimens confirmed the occurrence of seven species of the genus Sphenomorphus in southern Vietnam as follows:

\section{Sphenomorphus annamiticus (Boettger, 1901)}

Starry forest skink, thằn lằn phê-nô trung bộ (Figure 1F).

Type locality: "Phuc-Son in Annam" (now Phuoc Son District in Quang Nam Province) ${ }^{19}$.

Specimens examined $(n=2)$. ITBCZ 883 , male, Ta Kou, Ham Thuan Nam Dist., Binh Thuan Prov., $242 \mathrm{~m}$ a.s.l.; ITBCZ 352, juvenile, Lo Go-Xa Mat, Tan Bien Dist., Tay Ninh Prov. 

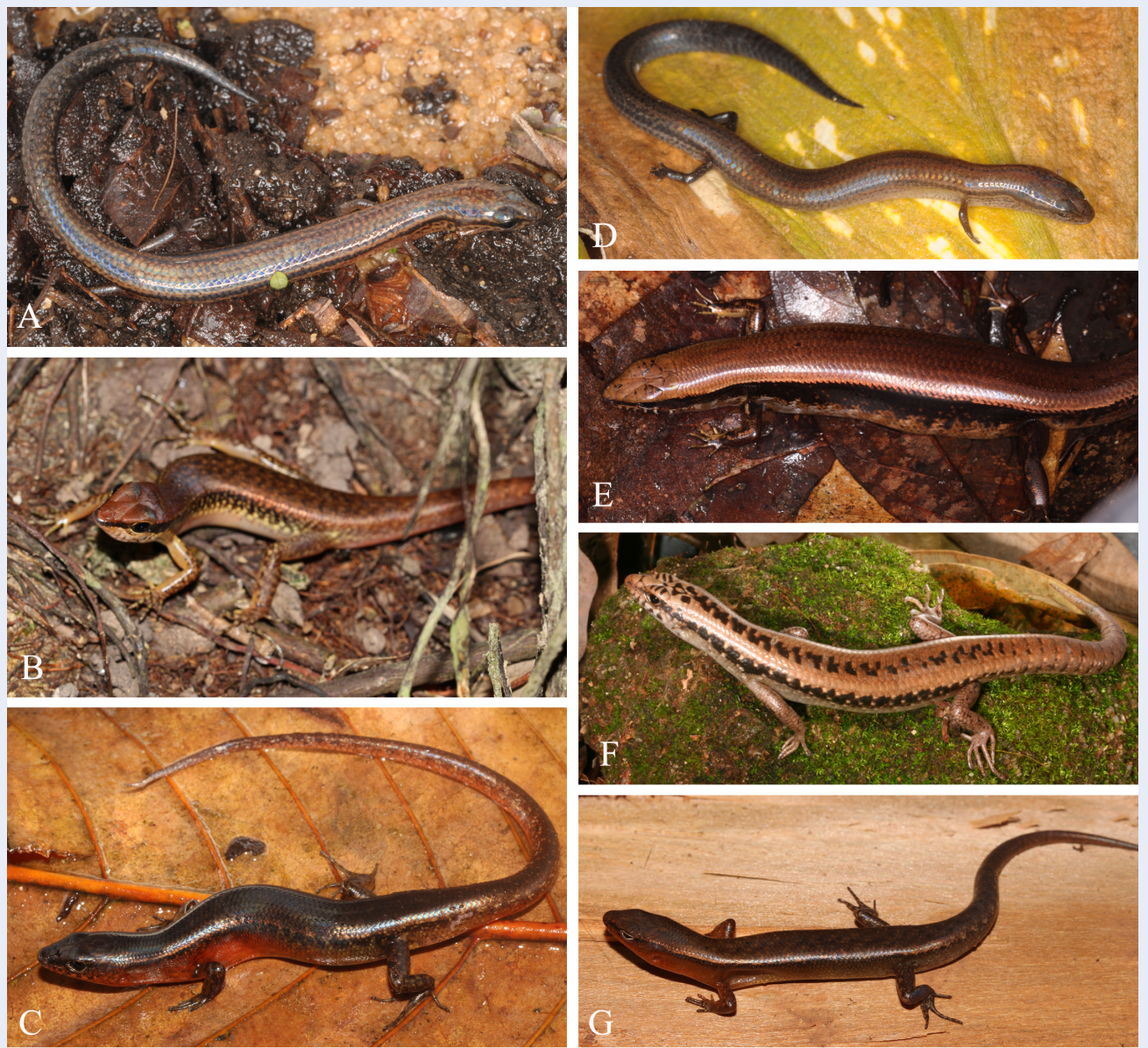

Figure 1: Skinks of genus Sphenomorphus in southern Vietnam. (A) S. tridigitus (ITBCZ 5307) from top of Bach Ma Mountains, Phu Loc Dist., Thua Thien-Hue Prov.; (B) S. maculatus (ITBCZ 6057) from Phu Quoc Island, Kien Giang Prov.; (C) S. yersini (ITBCZ 5685) from Hon Ba, CamLam Dist., Khanh Hoa Prov.; (D) S. sheai (ITBCZ 4563) from Tram Lap Forest, K'Bang Dist., Gia Lai Prov.; (E) S. indicus (ITBCZ 6835) from Nam Nung, Dak Glong Dist., Dak Nong Prov.; (F) S. annamiticus (ITBCZ 883) from Ta Kou, Ham Thuan Nam Dist., Binh Thuan Prov.; and (G) S. buenloicus (ITBCZ 6027) fromTram Lap Forest, K'Bang Dist., Gia Lai Prov.

Diagnosis. Relatively large-sized skink (SVL up to $65 \mathrm{~mm}$ ); depressed limbs overlap; rostral convex, in broad contact with the frontonasal; prefrontals separated from one another; no supranasals; four large supraoculars; two or three pairs of nuchals; ear oval, without or with short projecting lobules; dorsal scale rows enlarged, 22 mid-body scale rows, all smooth; two enlarged precloacal shields; limbs well developed, pentadactyl, and 18 or 19 lamellae beneath fourth toe. These characters agree with the previous descriptions $^{4,19}$.

Distribution. In southern Vietnam, S. annamiticus has been recorded from the following provinces: Kon Tum: Chu Mon Ray, Kon Plong; Quang Nam: Phuoc Son; Lam Dong: Da Lat ${ }^{10,17,20}$; Binh Thuan: Ta Kou; and Tay Ninh: Lo Go-Xa Mat [this study].
Natural history. All specimens were collected at night under rotting leaf layer near the trail in evergreen forest.

\section{Sphenomorphus buenloicus Darevsky \& Nguyen, 1983}

Buonluoi forest skink, thằn lằn phê-nô buôn lưới (Figure 1G).

Type locality: "Buon-Loi, Dalai Kontum Province" (now Buon Luoi, K’Bang District, Gia Lai Province), Vietnam $^{21}$.

Specimens examined $(n=4)$. ITBCZ 4357, female, Tram Lap Forest, 1263 m a.s.l., ITBCZ 6027, male, Tram Lap Forest, 1197 m a.s.l., and ITBCZ 5060, female, Dak Rong, 1311 m a.s.l., K’Bang Dist., Gia Lai Province (Prov.); ITBCZ 6832, female, Song Thanh, 
Nam Giang Dist., Quang Nam Prov., 361 m a.s.l.

Diagnosis. Relatively small size (SVL up to $56 \mathrm{~mm}$ ); depressed limbs overlap; prefrontals in contact with each other; four supraoculars; parietals shields contacting behind interparietal; one enlarged anterior temporal, two posterior temporals, the lower scale overlapping the upper one; no enlarged dorsal scale rows, 32-34 mid-body scale rows, all smooth; two enlarged precloacal shields; limbs well developed, pentadactyl, 16-19 lamellae beneath fourth toe; hemipenis smooth, forked at the middle point of its length with two developing lobes and the outer lobe is slightly longer than the inner one. These characters agree with the previous descriptions ${ }^{2,21}$.

Distribution. In southern Vietnam, S. buenloicus has been recorded from the following provinces: Gia Lai: Buon Luoi $^{21}$, Kon Chu Rang, Kon Ka Kinh ${ }^{22}$, Tram Lap, Dak Rong [this study]; Kon Tum: Kon Plong 5,17, Chu Mom Ray ${ }^{20,22}$; and Quang Nam: Song Thanh [this study].

Natural history. All specimens were collected at night and in daytime, under rotting leaf layer in evergreen forest.

\section{Sphenomorphus indicus (Gray, 1853)}

Indian forest skink, thằn lằn phê-nô ấn độ (Figure 1E).

Type locality: Sikkim, Himalayas, India ${ }^{23}$.

Specimens examined $(n=10)$. ITBCZ 5195 \& 5205, Bach Ma, Phu Loc Dist., Thua Thien-Hue Prov., 10001300 m a.s.l.; ITBCZ 6833, female, Ba Na, Da Nang City, 1477 m a.s.l.; ITBCZ 6834, female, Song Thanh, Nam Giang Dist., Quang Nam Prov., 361 m a.s.l.; ITBCZ 4262 \& 4568, Tram Lap, K’Bang Dist., Gia Lai Prov.; ITBCZ 2811, male, 1507 m a.s.l., ITBCZ 5689, Juv., $867 \mathrm{~m}$ a.s.l., ITBCZ 5696, juv., $1510 \mathrm{~m}$ a.s.l., Hon Ba, Cam Lam Dist., Khanh Hoa Prov.; ITBCZ 6835, female, Nam Nung, Dak Glong Dist., Dak Nong Prov., $865 \mathrm{~m}$ a.s.l.

Diagnosis. Large-sized skink (SVL up to $90 \mathrm{~mm}$ ); depressed limbs overlap; rostral convex, in broad contact with the frontonasal; prefrontals always separated from one another; no nuchals; four large supraoculars; ear oval, no projecting lobules; no enlarged dorsal scale rows, 30-38 mid-body scale rows, all smooth; two enlarged precloacal shields; limbs well developed, pentadactyl, 16-22 lamellae beneath fourth toe; hemipenis smooth, forked at about half of its length with two long lobes. These characters agree with the previous description ${ }^{10}$. Data on hemipenis are new. Distribution. In southern Vietnam, S. indicus has been recorded from the following provinces: Thua
Thien-Hue: Bach Ma; Da Nang: Ba Na ( ${ }^{17}$, [this study]; Quang Nam: Song Thanh [this study]; Quang Ngai: Son Ha, Ba To ${ }^{24}$; Kon Tum: Kon Plong ${ }^{17}$; Gia Lai: Tram Lap [this study]; Dak Lak: Chu Yang Sin ${ }^{17}$; Dak Nong: Nam Nung; Khanh Hoa: Hon Ba [this study]; and Dong Nai: Cat Tien ${ }^{17}$.

Natural history. All specimens were collected at night and in daytime, under rotting leaf layer in evergreen forest and in daytime near the road on top of mountains.

\section{Sphenomorphus maculatus (Blyth, 1853)}

Spotted forest skink, thằn lằn phê-nô đốm (Figure 1B).

Type locality: Asám (now Assam, India) ${ }^{25}$.

Specimens examined $(n=16)$. ITBCZ 6836 \& 6837, females, Chu Yang Sin, Krong Bong Dist., Dak Lak Prov., 480 m a.s.l.; ITBCZ 5780, female, Tan Nghia, Ham Tan Dist., Binh Thuan Prov., 100 m a.s.l.; ITBCZ 1221-1224, Ta Kou, Ham Thuan Nam Dist., Binh Thuan Prov., 54 m a.s.l.; ITBCZ 6284-6287, Ba Den, Duong Minh Chau Dist., Tay Ninh Prov., 365 m a.s.l.; ITBCZ 528, Chua Chan, Xuan Loc Dist., Dong Nai Prov., 473 m a.s.l.; ITBCZ 6348, female, Nui Dinh, Tan Thanh Dist., Ba Ria-Vung Tau Prov., 304 m a.s.l.; ITBCZ 6056-6058, males, Phu Quoc Island, Kien Giang Prov., $66 \mathrm{~m}$ a.s.l.

Diagnosis. Medium-sized skink (SVL up to 62 $\mathrm{mm}$ ); depressed limbs overlap; rostral concave, in broad contact with the frontonasal; prefrontals rather small, separated from one another; no nuchals; five supraoculars, first longest, fifth smallest; ear without projecting lobules; 38-42 mid-body scale rows, all smooth; dorsal scales larger than lateral ones; two enlarged precloacal shields; limbs well developed, pentadactyl, 16-22 lamellae beneath fourth toe; hemipenis smooth, forked at the middle point of its length with two long lobes. These characters agree with the previous description ${ }^{10}$. Data on hemipenis are new.

Distribution. In southern Vietnam, S. maculatus has been recorded from the following provinces: Dak Lak: Chu Yang Sin [this study]; Lam Dong: Da Lat ${ }^{17}$; Binh Thuan: Tan Nghia, Ta Kou [this study]; Dong Nai: Cat Tien ${ }^{17}$, Chua Chan [this study]; Tay Ninh: Ba Den; Ba Ria-Vung Tau: Nui Dinh [this study]; and Kien Giang: Hon Thom ${ }^{17}$, Phu Quoc [this study].

Natural history. All specimens were collected at night and in daytime under rotting leaf layer or rocky area in evergreen, semi-deciduous or disturbed forests and in hilly habitats near resident area. 
Sphenomorphus sheai Nguyen, Nguyen, Devender, Bonkowski \& Ziegler, 2013

Shea's forest skink, thằn lằn phê-nô shea (Figure 1D). Type locality: border area between Quang Ngai and Kon Tum provinces, Vietnam ${ }^{7}$.

Specimens examined $(n=3)$. ITBCZ 4563, 4564, and 6036, sex unknown, Tram Lap, K’Bang Dist., Gia Lai Prov., $997 \mathrm{~m}$ a.s.l.

Diagnosis. Small-sized skink (SVL up to $34.6 \mathrm{~mm}$ ); limbs short, pentadactyl, depressed limbs separated from each other; rostral concave, in broad contact with the frontonasal; prefrontals separated from one another; enlarged nuchals in two pairs; four, rarely three, supraoculars; supralabials six, the sixth largest, the first fused with nasal; infralabials five; primary temporal one; secondary temporals two, the lower scale overlapping the upper one; external ear openings absent; 20 mid-body scale rows, all smooth; paravertebral scales $54-58$, slightly larger than lateral ones; two enlarged precloacal shields, the left shield overlapping the right one; 8 or 9 lamellae beneath fourth toe; tail longer than snout-vent length $(\mathrm{TaL} / \mathrm{SVL}=1.6), 88$ transversally enlarged subcaudals; dorsolateral light stripe present on neck, shoulder, and anterior part of dorsum. Detailed morphological characters for the additional samples were showed inTable 1. These characters essentially agree with the original description ${ }^{7}$.

Distribution. In southern Vietnam, S. sheai has been recorded from the following provinces: Quang NgaiKon Tum border ${ }^{7}$ and Gia Lai: Tram Lap [this study]. Natural history. All specimens were collected at night under rotting leaf layer in evergreen forests.

\section{Sphenomorphus tridigitus (Bourret, 1939)}

Tridigital forest skink, thằn lằn phê-nô ba ngón (Figure 1A).

Type locality: Bach Ma, Thua Thien-Hue Province ${ }^{11}$. Specimens examined $(n=6)$. ITBCZ 5229, 5306 (gravid female), 5307, and 5308, Bach Ma, Phu Loc Dist., Thua Thien-Hue Prov., 1300 m a.s.l.; ITBCZ 7278 \& 7288, females, Ngoc Linh, Dak Glei Dist., Kon Tum Prov., $1825 \mathrm{~m}$ a.s.l.

Diagnosis. Small-sized skink (SVL up to $47.2 \mathrm{~mm}$ ); limbs short, depressed limbs separated, hindlimb pentadactyl, forelimb tridactyl; rostral concave, in broad contact with the frontonasal; prefrontals separated from one another; enlarged nuchals in two or three pairs; four supraoculars; supralabials six, the sixth largest, the first fused with nasal; infralabials five; primary temporal one; secondary temporals two, the lower scale overlapping or overlapped by the upper one; external ear openings absent; 20 mid-body scale rows, all smooth; paravertebral scales 51-63, slightly larger than lateral ones; two enlarged precloacal shields; seven or eight lamellae beneath fourth toe; tail longer than snout-vent length $(\mathrm{TaL} / \mathrm{SVL}=1.6), 87$ transversally enlarged subcaudals; a dorsolateral black stripe extending continuously from posterior margin of eye to tail base. Detailed morphological characters for the additional samples were showed in Table 1 . These characters essentially agree with the original and additional descriptions of the holotype ${ }^{11,13}$.

Distribution. In southern Vietnam, S. tridigitus has been recorded from the following provinces: Thua Thien-Hue: Bach Ma Mountains ${ }^{11}$, [this study]; Quang Nam: Ngoc Linh ${ }^{5,15}$; Kon Tum: Ngoc Linh [this study].

Natural history. All specimens were collected in the morning under leaf litter in mixed evergreen and pine forests around the Bach Ma summit and in evergreen forest in Ngoc Linh.

\section{Sphenomorphus yersini Nguyen, Nguyen, Nguyen, Orlov \& Murphy, 2018}

Yersin's forest skink, thằn lằn phê-nô yersin (Figure 1C).

Type locality: Hon Ba, Cam Lam, Khanh Hoa, Vietnam $^{2}$.

Specimens examined ( $\mathrm{n}=6)$. ITBCZ 5685, male, $1162 \mathrm{~m}$ a.s.l., ITBCZ 5686, female and ITBCZ 5684, male, 932 m a.s.l., Hon Ba, Cam Lam Dist., Khanh Hoa Prov.; ITBCZ 6838, male, Chu Yang Sin, Krong Bong Dist., Dak Lak Prov., 802 m a.s.l.; ITBCZ 6839, male, ITBCZ 6840, female, Nam Nung, Dak Glong Dist., Dak Nong Prov., 829 m a.s.l.

Diagnosis. Small-sized skink (SVL up to $56 \mathrm{~mm}$ ); depressed limbs overlap; rostral convex, in broad contact with the frontonasal; prefrontals in broad contact with or just touching one another; no nuchals; four, rarely five, supraoculars; ear oval, no projecting lobules; no enlarged dorsal scale rows, 32-34 midbody scale rows, all smooth; two enlarged precloacal shields; limbs well developed, pentadactyl, 1820 lamellae beneath fourth toe hemipenis smooth, deeply forked, asymmetrical with a long lobe and another short. These characters essentially agree with the original description ${ }^{2}$.

Distribution. In southern Vietnam, S. yersini has been recorded from the following provinces: Khanh Hoa: Hon $\mathrm{Ba}^{2}$; Dak Lak: Chu Yang Sin; and Dak Nong: Nam Nung [this study].

Natural history. All specimens were collected at night under rotting leaf layer in evergreen forest. 


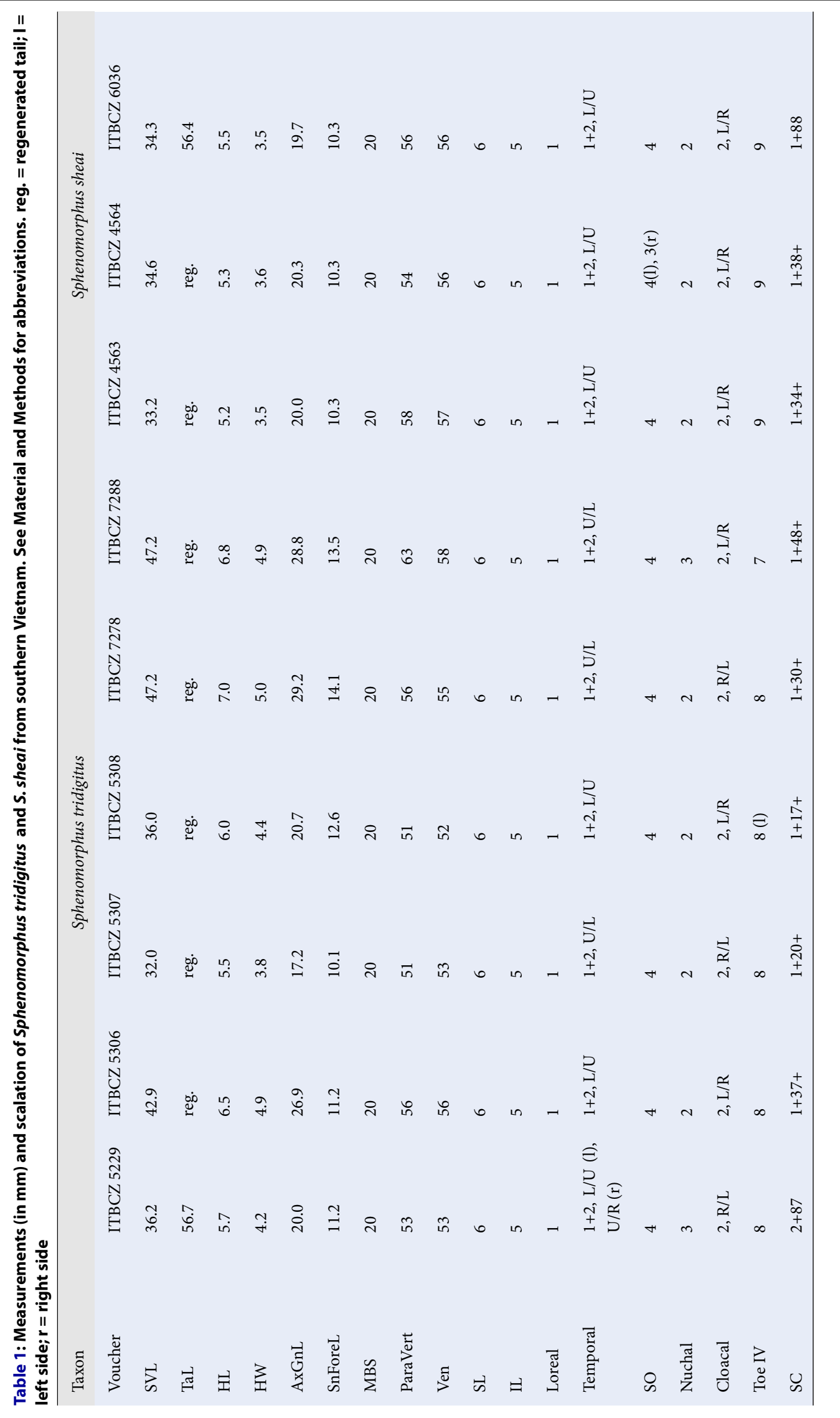




\section{DISCUSSION}

Taxonomic notes. Sphenomorphus stellatus was described under the name Lygosoma stellatum based on samples collected from Larut Hills, Perak, West Malaysia $^{26}$. One year later, Boettger ${ }^{19}$ described $L y$ gosoma annamiticum (=Sphenomorphus annamiticus) from "Phuc-son in Annam" (now Phuoc Son, Quang Nam). Smith ${ }^{10}$ supposed that $S$. annamiticus was a junior synonym of $S$. stellatus based on a specimen collected from Da Lat. However, S. annamiticus was recently resurrected for the populations in southern Vietnam based on molecular and morphological evidences and S. stellatus was reported to be restricted to Peninsular Malaysia ${ }^{4}$. Our specimens agree with the descriptions of S. annamiticus ${ }^{4,19}$.

Vassilieva et al. ${ }^{27}$ recorded Sphenomorphus cf. buenloicus from Lam Dong, Dong Nai, Ba Ria-Vung Tau, and Tay Ninh provinces, and subsequently Neang \& Poyarkov $^{22}$ reported S. buenloicus from Lam Dong (Loc Bac) and Dong Nai (Cat Tien) provinces. However, Nguyen et al. ${ }^{2}$ recently described Sphenomorphus yersini from Khanh Hoa and the key differences between $S$. buenloicus and S. yersini involve DNA sequences and morphology of the hemipenes. Hemipenes of the samples from Chu Yang Sin (Dak Lak) and Nam Nung (Dak Nong) are similar to those of S. yersini. Hence, further molecular studies are necessary to clarify if the previous records ${ }^{22,26}$ are $S$. buenloicus, S. yersini, or other taxa, and if S. buenloicus occurs in Gia Lai-Kon Tum Plateau and adjacent areas while S. yersini distributes in Lang Bian Plateau and its vicinity.

Sphenomorphus sheai was described from a single specimen ${ }^{7}$ and additional data from new specimens essentially agree with the original description. However, some characters differ from those of the holotype, including enlarged anterior temporal (1 vs. 2), loreal (1 vs. 2), paravertebral scales (54-58 vs. 53), and lamellae under toe four ( 8 or 9 vs. 6 ).

Some characters and variation differ between the Laotian specimen ${ }^{13}$ and samples from the type locality of $S$. tridigitus. The specimen from Laos has six pairs of subcaudals basally while the specimens from Bach Ma bear only one or two pairs. The samples from Bach Ma have from 51 to 56 paravertebral scale rows, which is greater than in the specimen from Laos (50). Uetz et al. ${ }^{3}$ noted that $S$. tridigitus differs from most of its congeners by having the upper temporal scale overlapping the lower one. This statement may have originated from Greer et al. ${ }^{13}$. However, additional material from the type locality reveals variation. In our four specimens from the type locality, only one
(ITBCZ 5307) has the upper temporal scale overlapping the lower one, two (ITBCZ $5306 \& 5308$ ) have the lower temporal scale overlapping the upper one, and the remainder (ITBCZ 5229) has the upper temporal scale overlapping the lower one on the right and opposite condition on the left. The significant difference between specimens from Laos and Bach Ma involves the number of mid-body scale rows. All examined specimens from the type locality as well as the holotype have 20 mid-body scale rows while sample form Laos has 18 rows only. Two additional samples from Ngoc Linh essentially agree with those from Bach Ma and, thus, they also differ from the Laotian specimen in having 20 mid-body scale rows. Given this invariability of mid-body scale rows (20 vs. 18), further molecular study should be done to clarify if populations from Bach Ma, Ngoc Linh, and Laos are distinct taxa.

New records of distribution. In total, we report 20 new locations in southern Vietnam for all seven species. The new records for each species are as follows: S. annamiticus: Ta Kou and Lo Go-Xa Mat; $S$. buenloicus: Tram Lap, Dak Rong, and Song Thanh; $S$. indicus: Song Thanh, Tram Lap, Nam Nung, and Hon Ba; S. maculatus: Chu Yang Sin, Tan Nghia, Ta Kou, Chua Chan, Ba Den, Nui Dinh, Phu Quoc; S. sheai: Tram Lap; S. tridigitus: Ngoc Linh; and S. yersini: Chu Yang Sin and Nam Nung. In general, these skinks trend to have wide distributions.

Hemipenis. Among seven species of Sphenomorphus in southern Vietnam, the hemipenes of two were described previously ${ }^{2,21}$ (S. buenloicus and S. yersini) and we add descriptions for S. indicus and S. maculatus. The organs can be divided into two groups. The first group has symmetrical hemipenes each with two long lobes. This form occurs in S. indicus and S. maculatus. The second group has asymmetrical hemipenes with the two lobes being different in length, as found in S. buenloicus and S. yersini. The hemipenes of S. annamiticus, S. sheai, and S. tridititus remain unknown. Main limitations of this study. Herein, we use only morphological data to access the taxonomic status of species of Sphenomorphus in southern Vietnam. All recorded species seem to have wide distributions and, therefore, further molecular studies should be done to clarify if cryptic species exist in the area. In addition, specimens of $S$. tridigitus from Laos were not examined in this study. Hence, it is still in doubt if this species is endemic to Vietnam or occurs in both Vietnam and Laos. Molecular study is necessary to clarify if populations in the two countries are distinct taxa or conspecific. 
Among seven species of Sphenomorphus in southern Vietnam, four are known their hemipenial structures. Further surveys need to collect more adult males of the three remaining species and others to obtain a comprehensive understanding of the hemipenial morphology of all species of Sphenomorphus.

\section{CONCLUSION}

We confirm the occurrence of seven skinks of the genus Sphenomorphus in southern Vietnam, including S. annamiticus, S. buenloicus, S. indicus, S. maculatus, S. sheai, S. tridigitus, and S. yersini and provide 20 new distributional records. In term of morphological characters, the newly collected specimens of $S$. sheai have one enlarged anterior temporal and eight or nine lamellae under fourth toe, which differs from the original description. Additional specimens of $S$. tridigitus from type locality in Bach Ma have 20 midbody scale rows, first supralabial and nasal fused, and upper temporal overlapped or overlapping the lower one. Hemipenis of known species form two groups, one with symmetrical long lobes and the other with asymmetrical lobes.

\section{COMPETING INTERESTS}

The authors declare that they have no competing interests.

\section{AUTHOR CONTRIBUTION}

Manh V. Le and Sang N. Nguyen designed this study, collected and analyzed data, and wrote the manuscript; Luan T. Nguyen, Ba D. Vo, Vu D.H. Nguyen, and R. W. Murphy collected data and gave comments on the manuscript.

\section{ACKNOWLEDGMENTS}

We would like to thank Truong Tan Tiep (Da Nang City), Nguyen Quoc Thang, and Le Thi Thanh Ngan (Ho Chi Minh City) for their assistance in the filed. This research is funded by the Vietnam Academy of Science and Technology under grant number ĐLTE00.07/18-19.

\section{REFERENCES}

1. Fitzinger L. Systema Reptilium - Fasciculus primus - Amblyglossae. Braumüller et Seidel, Vindodonae [Wienna];106 + VI:1843 [in German].

2. Nguyen SN, Nguyen LT, Nguyen VDH, et al. A new skink of the genus Sphenomorphus Fitzinger, 1843 (Squamata: Scincidae) from Hon Ba Nature Reserve, Southern Vietnam. Zootaxa. 2018;4438:313-326. PMID: 30313147. Available from: https: //doi.org/10.11646/zootaxa.4438.2.6.

3. Uetz P, Freed P, Hosek J. The Reptile Database; 2019. Available from: www.reptile-database.org.

4. Grismer LL, Wood PL, Quah ESH, et al. Integrative taxonomy of the Asian skinks Sphenomorphus stellatus (Boulenger, 1900) and S. praesignis (Boulenger, 1900) with the resurrection of
S. annamiticus (Boettger, 1901) and the description of a new species from Cambodia. Zootaxa. 2019;4683:381-411. PMID: 31715918. Available from: https://doi.org/10.11646/zootaxa. 4683.3.4.

5. Nguyen TQ, Schmitz A, Nguyen TT, et al. Review of the genus Sphenomorphus Fitzinger, 1843 (Squamata: Sauria: Scincidae) in Vietnam, with description of a new species from northern Vietnam and southern China and the first record of Sphenomorphus mimicus Taylor, 1962 from Vietnam. J Herpetol. 2011;45:145-154. Available from: https://doi.org/10.1670/09068.1 .

6. Nguyen TQ, Tran TT, Nguyen TT, et al. First record of Sphenomorphus incognitus (Thompson, 1912) (Squamata: Scincidae) from Vietnam with some notes on natural history. Asian Herpetol Res. 2012;3:147-150. Available from: https://doi.org/ 10.3724/SP.J.1245.2012.00147.

7. Nguyen TQ, Nguyen KV, Devender RWV, et al. A new species of Sphenomorphus Fitzinger, 1843 (Squamata: Sauria: Scincidae) from Vietnam. Zootaxa. 2013;3734:56-62. PMID: 25277895. Available from: https://doi.org/10.11646/zootaxa. 3734.1.6.

8. Bobrov VV. Checklist and bibliography of the lizards of Vietnam. Smithson Herpetol Inf Serv. 1995;105:1-28. Available from: https://doi.org/10.5479/si.23317515.105.1.

9. Bobrov VV, Semenov DV. Lizards of Vietnam. Moscow, Tovarishestvo Nauchnih Izdanii KMK [in Russian];225+XVIII:2008.

10. Smith MA. The Fauna of British India, Including Ceylon and Burma. Sauria. London, Taylor and Francis xiii + 440pp + 1pl. 1935. Reptilia and Amphibia;Il.

11. Bourret R. Notes herpétologiques sur I'Indochine française. XVIII. Reptiles et batraciens reçus au laboratoire des Sciences naturelles de l'Université au cours de l'année 1939. Descriptions de quatre espèces et d'une variété nouvelles. Bulletin général de l'Instruction publique, Hanoi, 19e Année (4, décembre). Annexe. 1939;1 pl.:5-39 [in French].

12. Teynie A, David $P$, Ohler A, Luanglath $K$. Notes on a collection of amphibians and reptiles from southern Laos, with a discussion of the occurrence of Indo-Malayan species. Hamadryad. 2004;29:33-62.

13. Greer AE, David $P$, Teynie A. The Southeast Asian scincid lizard Saiphos tridigitus Bourret, 1939 (Reptilia, Scincidae): a second specimen. Zoosystema. 2006;28:785-790.

14. Heatwole H, Stuart BL. High densities of a "rare" skink. Herpetol Rev. 2008;39:169-170.

15. Bain RH, Nguyen TQ, Doan KV. New herpetofaunal records from Vietnam. Herpetol Rev. 2007;38:107-117.

16. Nguyen TQ, Nguyen SV, W B, Ziegler T. A new species of Scincella (Squamata: Scincidae) from Vietnam. Folia Zool. 2010;59:115-121. Available from: https://doi.org/10.25225/ fozo.v59.i2.a6.2010.

17. Nguyen SV, Ho CT, Nguyen TQ. Herpetofauna of Vietnam. Frankfurt am Main, Edition Chimaira. 2009;p. 768.

18. Ouboter PE. A revision of the genus Scincella (Reptilia: Sauria: Scincidae) of Asia, with some notes on its evolution. Zool Verh. 1986;229:3-66.

19. Boettger O. Aufzahlung einer liste von reptilien und batrachiern aus Annam. Senckenberg Nat Gesell [in German]. 1901;1901:45-53.

20. Jestrzemski D, Schutz S, Nguyen TQ, Ziegler T. A survey of amphibians and reptiles in Chu Mom Ray National Park, Vietnam, with implications for herpetofaunal conservation. Asian J Conserv Biol. 2013;2:88-110.

21. Darevsky IS, Nguyen SV. New and little known lizard species from Vietnam. Zool Zhur. 1983;62:1827-1837 [in Russian].

22. Neang T, Poyarkov NA. First record of the Buonluoi forest skink Sphenomorphus buenloicus Darevsky \& Nguyen. 1983 (Squamata: Scincidae) from Cambodia Cambodian J Nat Hist. 2016;2016:114-118.

23. Gray JE. Descriptions of some undescribed species of reptiles collected by Dr. Joseph Hooker in the Khassia Mountains, East Bengal, and Sikkim Himalaya. Ann Mag Natl Hist. 
1853;12:386-392. Available from: https://doi.org/10.1080/ 03745485709495063 .

24. Nemes L, Babb R, Devender W, et al. First contribution to the reptile fauna of Quang Ngai Province, central Vietnam. Biodivers J. 2013:4:301-326.

25. Blyth $E$. Notices and descriptions of various reptiles, new or little-known. J Asiat Soc Bengal. 1853;22 [1854]:639-655.
26. Boulenger GA. Descriptions of new batrachians and reptiles from the Larut Hills, Perak. Ann Mag Nat Hist. 1900;6:186-193. Available from: https://doi.org/10.1080/00222930008678356.

27. Vassilieva AB, Galoyan EA, Poyarkov NA, Geissler P. A Photographic Field Guide to the Amphibians and Reptiles of the Lowland Monsoon Forests of Southern Vietnam. Frankfurt am Main, Edition Chimaira. 2016;p. 324 